\title{
Determinants of patient preferences for total knee replacement: African-Americans and whites
}

C. Kent Kwoh" ${ }^{*}$, Ernest R. Vina ${ }^{1}$, Yona K. Cloonan², Michael J. Hannon ${ }^{3}$, Robert M. Boudreau ${ }^{2}$ and Said A. Ibrahim ${ }^{4}$

\begin{abstract}
Introduction: Patient preferences contribute to marked racial disparities in the utilization of total knee replacement (TKR). The objectives of this study were to identify the determinants of knee osteoarthritis (OA) patients' preferences regarding TKR by race and to identify the variables that may mediate racial differences in willingness to undergo TKR.

Methods: Five hundred fourteen White (WH) and 285 African-American (AA) patients with chronic knee pain and radiographic evidence of OA participated in the study. Participants were recruited from the community, an academic medical center, and a Veterans Affairs hospital. Structured interviews were conducted to collect socio-demographics, disease severity, socio-cultural determinants, and treatment preferences. Logistic regression was performed, stratified by race, to identify determinants of preferences. Clinical and socio-cultural factors were entered simultaneously into the models. Stepwise selection identified factors for inclusion in the final models $(p<0.20)$.

Results: Compared to WHs, AAs were less willing to undergo TKR ( $80 \%$ vs. $62 \%$, respectively). Better expectations regarding TKR surgery outcomes determined willingness to undergo surgery in both AAs (odds ratio (OR) 2.08, $95 \%$ confidence interval (Cl) 0.91-4.79 for $4^{\text {th }}$ vs. $1^{\text {st }}$ quartile) and WHs (OR 5.11, $95 \% \mathrm{Cl} 2.31-11.30$ for $4^{\text {th }} \mathrm{vs} 1^{\text {st }}$ quartile). Among AAs, better understanding of the procedure (OR 1.80, $95 \% \mathrm{Cl}$ 0.97-3.35), perceiving a short hospital course (OR 0.81, $95 \% \mathrm{Cl} 0.58-1.13$ ), and believing in less post-surgical pain (OR 0.73, $95 \% \mathrm{Cl} 0.39-1.35$ ) and walking difficulties (OR 0.66, $95 \% \mathrm{Cl}$ 0.37-1.16) also determined willingness. Among WHs, having surgical discussion with a physician (OR 1.96, $95 \% \mathrm{Cl} 1.05-3.68)$, not ever receiving surgical referral (OR 0.56, $95 \% \mathrm{Cl} 0.32-0.99)$, and higher trust in the healthcare system (OR 1.58, $95 \% \mathrm{Cl} 0.75-3.31$ for $4^{\text {th }}$ vs. $1^{\text {st }}$ quartile) additionally determined willingness. Among the variables considered, only knowledge-related matters pertaining to TKR attenuated the racial difference in knee OA patients' treatment preference.
\end{abstract}

Conclusions: Expectations of surgical outcomes influence preference for TKR in all patients, but clinical and socio-cultural factors exist that shape marked racial differences in preferences for TKR. Interventions to reduce or eliminate racial disparities in the utilization of TKR should consider and target these factors.

Keywords: Osteoarthritis, Knee replacement surgery, Race, Health disparity, Treatment preference

\footnotetext{
* Correspondence: CKwoh@arthritis.arizona.edu

'University of Arizona School of Medicine and University of Arizona Arthritis Center, 1501 N. Campbell Ave., PO Box 245093, Tucson, Arizona 85724, USA Full list of author information is available at the end of the article
} 


\section{Introduction}

Osteoarthritis (OA) is a highly prevalent and disabling disease, and the lifetime risk of developing knee OA is one in two [1-3]. When conservative therapies no longer provide lasting pain relief, total knee replacement (TKR) becomes a very effective treatment option [4]. Despite its efficacy, there are marked racial disparities in the utilization of TKR. Using Medicare claims data, it has been estimated that the annual rate of TKR was 4.84 per 1000 among African-American (AA) women, compared to 5.97 per 1000 among white (WH) women [5]. The rate for AA men (1.84 per 1000) was also lower than that for WH men (4.82 per 1000). Analyzing Medicare data from other time periods and data from other national databases have elicited similar findings [5-8].

Reasons for racial disparities in TKR utilization rate are complex and involve patient-level, provider-level, and system-level factors [7]. Patient preference has emerged as a key factor, however. It is a strong predictor of time to receipt of a first total joint replacement [9]. Patient preference in joint replacement may also vary by race, sex, and other sociodemographic factors [10-16]. In studies of veterans with advanced knee or hip OA, AAs were consistently less willing to consider joint replacement compared to WHs [10-13]. In a focus group study of AA patients' attitudes and preferences in arthritis care, AAs expressed preferences for natural remedies and against undergoing surgery [17].

Patient preference is largely an attitudinal disposition [7]. According to the expectancy-value model, attitudes arise spontaneously and inevitably as we form beliefs about an object [18]. Our overall attitude towards an object is determined by the subjective value of the object's attributes in relation to the depth of the association [18]. Hence, racial differences in treatment preferences in TKR are likely due to varying beliefs or opinions about the procedure and the healthcare system. Studies have shown racial variations in knowledge and expectations of joint replacement [11, 19-21]. WHs are more likely to believe that TKR is efficacious and are more likely to be familiar with the procedure than AAs [11, 20, 21]. AAs are more likely to expect surgical complications [11, 21]. AAs are also less likely to be satisfied with their communication with orthopedic surgeons than WHs [22].

Moreover, studies have investigated some of the correlates of willingness to undergo joint replacement. Patients' perceptions of appropriateness of surgery and of high efficacy and acceptable risks when undergoing joint replacement are all strongly associated with willingness to consider the procedure $[16,20]$. Discussing the procedure and receiving a recommendation from a physician may also determine willingness to undergo joint replacement $[15,20]$. High trust in physicians may also increase willingness [20]. Despite such evidence, the specific socio- cultural beliefs that impact patients' willingness to consider TKR as a treatment option, by patient race, remain unclear, as do the factors that explain racial differences in treatment preferences in TKR.

The primary objective of this study is to examine the roles of patients' knowledge of TKR, beliefs about TKR, attitudes towards TKR, attitudes towards providers, and attitudes towards the healthcare system, in determining willingness to undergo TKR, by patient race. The secondary objective is to determine which of these factors could mediate racial differences in willingness to undergo TKR.

\section{Methods}

Participants were recruited from the University of Pittsburgh and the Veterans Affairs (VA) Pittsburgh Healthcare System clinics. They were also sought through mailings and local advertisements. The recruitment methodology has been previously reported [23]. The study was approved by the University of Pittsburgh and VA Institutional Review Boards. Informed consent was obtained from all participants in the study.

Inclusion criteria included: $\mathrm{AA}$ or $\mathrm{WH}$ race, age $\geq 50$ years, presence of chronic frequent knee pain [24], moderate-to-severe knee OA based on Western Ontario McMaster Index (WOMAC) summary score $\geq 39$ [25], radiographic evidence of OA (i.e., Kellgren-Lawrence grade $\geq 2$ ) [26], and presence of knee OA according to American College of Rheumatology [27] criteria. Exclusion criteria included: history of major joint replacement, terminal illness, inflammatory arthritis, or dementia. Patients participated in a face-to-face interview.

\section{Key study variables}

To determine willingness to undergo TKR, participants were asked: "If your knee pain were ever to get severe, would you be willing to have surgery to replace your knee if your doctor recommended it?" [28]. This item used a five-category ordinal response scale. Responses were dichotomized to willing ("definitely willing" and "probably willing") or unwilling ("unsure," "probably not willing" and "definitely not willing") [12, 23]. The primary predictor variable was self-identified race (AA or WH).

\section{Study covariates}

Socio-demographics

Socio-demographic characteristics included age, sex, marital status, household income, education, employment status, and type(s) of health insurance. Functional social support was measured using the 5-item modified Medical Outcomes Study-social support scale (MOS-SSS) [29]. Higher scores suggest more social support (range 0-20). 


\section{Clinical information}

OA-related disease severity was assessed using the 24-item WOMAC [25]. Higher summary scores indicate increased pain, stiffness and functional limitations (range 0-100). Comorbid conditions were weighted and summed using a modified Charlson co-morbidity index [30]. Quality of life was assessed using the Short Form Health Survey (SF-12v2, range 0-100) [31]. Depression was assessed using the Patient Health Questionnaire-9 (PHQ-9, range 0-27) [32].

\section{Potential mediator variables \\ Religiosity}

Religiosity was measured using a 4-item scale that assesses people's religious behavior and self-identification [33]. Higher scores indicate greater levels of religiosity (range 0-14).

\section{Knowledge of TKR}

To assess familiarity with TKR, and perceptions of benefits and risks of TKR, participants were asked questions that were previously used to assess knowledge ( 3 items) and perceptions (5 items) of joint replacement [11]. To assess TKR outcome expectations, we used the Hospital for Special Surgery (HSS) Knee Replacement Expectations Survey [34]. The total score ranges from 0-76, with 76 being the highest expectation.

\section{TKR utilization process}

The following yes/no questions were asked: 1) "Has your doctor ever discussed surgery to replace your knee?"; 2) "Has your doctor ever referred you to an arthritis specialist?"; 3) "Has your doctor ever referred you to a surgeon that specializes in arthritis?"; 4) "Have any of your doctors ever recommended surgery to replace your knee?"

\section{Trust in providers and healthcare system}

Trust in physicians was determined using an 11-item scale (range 11-55) [35]. Trust in the healthcare system was assessed using the 9-item Health Care System Distrust measure (range 9-45). Higher summary scores indicate stronger trust in both measures.

\section{Statistical analysis}

Socio-demographic and clinical characteristics were compared by race, using $t$ tests or Wilcoxon rank-sum tests for continuous variables and Pearson chi square $\left(\mathrm{x}^{2}\right)$ tests for categorical variables. In the same manner, all patientreported knowledge, attitudes and beliefs measured were contrasted by willingness.

\section{Association of race with willingness to undergo TKR}

Unadjusted and adjusted logistic regression models were used to evaluate the association of willingness and race. Covariates for adjusted models were selected a priori, which included recruitment site, age, sex, income, and WOMAC total score [12]. Additional covariates considered for adjusted models included education, employment, health insurance, comorbidities, social support, and mental health status. Variables associated with both willingness and race $(p<0.10)$ in bivariate comparisons were entered simultaneously into the model. Forward stepwise selection $(p<0.10)$ was used to select covariates to include in a final adjusted model. Statistical significance for the main effect of race on willingness was calculated using likelihood ratio (LR) tests.

\section{Association of potential mediators with willingness to undergo TKR}

Separate adjusted logistic regression models were used to assess the association between willingness to undergo TKR and religiosity, trust in physicians, trust in healthcare, expectations of TKR, familiarity with TKR, perceptions of benefits and risks of TKR, and TKR utilization process measures. Because a summary score for the TKR-related knowledge measures (except for expectations of TKR) were unavailable, all TKR-related knowledge items were entered simultaneously into a multivariable model. Stepwise selection $(p<0.20)$ was used to identify knowledge-related items and TKR utilization process items to be retained in subsequent models. Statistical significance was evaluated using LR tests.

Next, potential mediators were entered simultaneously into a single model. Only TKR knowledge items and utilization process items that were significantly associated with willingness to undergo TKR (based on previous models) were considered for inclusion. Stepwise selection $(p<0.20)$ was used to identify which variables to include in subsequent models. An LR test was used to test whether these variables were associated with willingness. Analyses were run using data from all participants then stratified by race. Any variable associated with willingness to undergo TKR in more than one model (full, WHs only, AAs only) was selected for inclusion in the mediation model.

\section{Mediation analysis}

Potential mediators were entered (individually and simultaneously) into the initial adjusted logistic regression model (i.e., willingness $=$ race + covariates + mediator(s) $)$. Any item identified by at least one of the stepwise models described above was included as a mediating variable in the mediation models. Attenuation of the estimated odds ratios before and after inclusion of the variables ( $>10 \%$ change) provided evidence for mediation of the association between race and willingness to undergo TKR [36]. In all regression models, $95 \%$ confidence intervals were calculated using robust variance estimates. Statistical significance was set with $\alpha$ of 0.05 . 
Analyses were performed using STATA 12.0 (StataCorp LP).

\section{Results}

Participants included 514 WH and 285 AA patients with knee OA. AA participants were younger and more likely to be unemployed or disabled (Table 1). At screening, they also had higher WOMAC total, higher PHQ-9 depression, and lower SF-12 physical health scores.

\section{Bivariate associations between potential mediations and willingness}

Among all participants, several TKR-related knowledge items were associated with willingness to undergo surgery, including having family/friend who had had joint surgery and reporting a good understanding of TKR (Table 2). Believing in a shorter duration of hospital stay $(p=0.023)$, lower post-surgical pain $(p<0.001)$, and less difficulty walking after surgery $(p<0.001)$ were all associated with willingness to consider TKR. Those willing to

Table 1 Participant characteristics by race

\begin{tabular}{|c|c|c|c|}
\hline Characteristic & White $(n=514)$ & African-American $(n=285)$ & $P$ value $^{a}$ \\
\hline \multicolumn{4}{|l|}{ Socio-demographic characteristics } \\
\hline Age, mean $\pm S D$, years & $64.54 \pm 9.39$ & $58.68 \pm 8.13$ & $<0.001$ \\
\hline Sex, n (\%) female & $302(58.8)$ & $207(72.6)$ & $<0.001$ \\
\hline Currently married, n (\%) & $275(53.5)$ & $65(22.8)$ & $<0.001$ \\
\hline Education, n (\%) & & & $<0.001$ \\
\hline$\leq$ High school or GED & $200(39.1)$ & $170(60.1)$ & \\
\hline Post-secondary training, Associates/Bachelors degree & $194(38.0)$ & $98(34.6)$ & \\
\hline Graduate degree & $117(22.9)$ & $15(5.3)$ & \\
\hline Income, n (\%) & & & $<0.001$ \\
\hline$<\$ 10,000$ & $32(6.9)$ & $84(31.7)$ & \\
\hline$\$ 10,000-\$ 19,999$ & $72(15.6)$ & $83(31.3)$ & \\
\hline$\$ 20,000-\$ 29,999$ & $75(16.2)$ & $35(13.2)$ & \\
\hline$\$ 30,000-\$ 39,999$ & $50(10.8)$ & $17(6.4)$ & \\
\hline$\$ 40,000-\$ 49,999$ & $51(11.0)$ & $12(4.5)$ & \\
\hline$\geq \$ 50,000$ & $183(39.5)$ & $34(12.8)$ & \\
\hline Employment status, n (\%) & & & $<0.001$ \\
\hline Full time & $145(28.4)$ & $70(24.6)$ & \\
\hline Part time & $51(10.0)$ & $23(8.1)$ & \\
\hline Unemployed & $36(7.0)$ & $46(16.2)$ & \\
\hline Disabled & $53(10.4)$ & $81(28.5)$ & \\
\hline Retired & $226(44.2)$ & $64(22.5)$ & \\
\hline \multicolumn{4}{|l|}{ Health insurance ${ }^{b}, \mathrm{n}(\%)$} \\
\hline Medicare & $225(46.2)$ & $98(35.5)$ & 0.004 \\
\hline Medicaid & $53(11.2)$ & $63(22.9)$ & $<0.001$ \\
\hline HMO or private/group & $381(77.6)$ & $161(57.7)$ & $<0.001$ \\
\hline No insurance & $12(2.6)$ & $21(7.7)$ & 0.001 \\
\hline MOS social support, mean \pm SD & $15.17 \pm 4.79$ & $13.44 \pm 5.26$ & $<0.001$ \\
\hline Recruitment site, n (\%) non-Veterans Affairs & $467(90.9)$ & $278(97.5)$ & $<0.001$ \\
\hline \multicolumn{4}{|l|}{ Clinical characteristics } \\
\hline WOMAC, mean $\pm S D$ & $42.98 \pm 15.27$ & $53.98 \pm 15.10$ & $<0.001$ \\
\hline Comorbidities, mean number \pm SD & $3.22 \pm 1.71$ & $3.56 \pm 1.69$ & 0.007 \\
\hline PHQ-9 depression, mean \pm SD & $4.77 \pm 4.67$ & $6.63 \pm 5.5$ & $<0.001$ \\
\hline SF-12 physical health, mean \pm SD & $38.50 \pm 11.01$ & $36.25 \pm 10.00$ & 0.0045 \\
\hline
\end{tabular}

$\overline{{ }^{a} P}$ value from Pearson chi square or $t$ test. ${ }^{\mathrm{b}}$ Individuals may be included in multiple categories. MOS Medical Outcomes Study, PHQ-9 Patient Health Questionnaire, SF MOS 12-Item Short Form Health Survey, WOMAC Western Ontario McMaster Index, GED General Educational Development test, HMO Health Maintenance Organization 
Table $\mathbf{2}$ Characteristics of OA patients by willingness to undergo TKR

\begin{tabular}{|c|c|c|c|}
\hline & Not willing $(n=208)$ & Willing $(n=585)$ & $P$ value $^{a}$ \\
\hline \multicolumn{4}{|l|}{ Socio-demographic Characteristics } \\
\hline Race, n (\%) African-American & $106(51.0)$ & $176(30.1)$ & $<0.001$ \\
\hline Age, mean $\pm S D$, years & $62.88 \pm 10.64$ & $62.28 \pm 8.87$ & 0.467 \\
\hline Education, n (\%) & & & 0.008 \\
\hline$\leq$ High School or GED & $115(55.3)$ & $254(43.4)$ & \\
\hline Post-secondary/Associates/Bachelors & $69(33.2)$ & $219(37.4)$ & \\
\hline graduate degree & $22(10.6)$ & 109 (18.6) & \\
\hline Income, n (\%) & & & $<0.001$ \\
\hline$<\$ 10,000$ & $39(21.3)$ & $76(14.1)$ & \\
\hline$\$ 10,000-\$ 19,999$ & $56(30.6)$ & $97(18.0)$ & \\
\hline$\$ 20,000-\$ 29,999$ & $21(11.5)$ & $88(16.3)$ & \\
\hline$\$ 30,000-\$ 39,999$ & $19(10.4)$ & $48(8.9)$ & \\
\hline$\$ 40,000-\$ 49,999$ & $16(8.7)$ & $47(8.7)$ & \\
\hline$\geq \$ 50,000$ & $32(17.5)$ & $183(34)$ & \\
\hline Employment status, n (\%) & & & 0.006 \\
\hline Full time & $40(19.2)$ & $174(29.9)$ & \\
\hline Part time & $17(8.2)$ & $57(9.8)$ & \\
\hline Unemployed & $34(16.3)$ & $48(8.3)$ & \\
\hline Disabled & $40(19.2)$ & $92(15.8)$ & \\
\hline Retired & $77(37.0)$ & $210(36.1)$ & \\
\hline \multicolumn{4}{|l|}{ Health insuranceb, n (\%) } \\
\hline Medicare & $93(46.3)$ & $227(40.8)$ & 0.181 \\
\hline Medicaid & $37(19.0)$ & $78(14.2)$ & 0.114 \\
\hline Private/group & $81(42.0)$ & $292(52.9)$ & 0.009 \\
\hline No insurance & $14(7.6)$ & $19(3.5)$ & 0.021 \\
\hline Recruitment site, n (\%) non-Veterans Affairs & $196(94.2)$ & $543(92.8)$ & 0.2247 \\
\hline \multicolumn{4}{|l|}{ Knowledge, attitudes and beliefs } \\
\hline Religiosity, mean \pm SD & $10.19 \pm 3.78$ & $9.59 \pm 4.00$ & 0.053 \\
\hline \multicolumn{4}{|l|}{ Knowledge of TKR: familiarity, n (\%) yes } \\
\hline Heard about hip/knee surgery & $158(76.7)$ & $458(79.0)$ & 0.497 \\
\hline Family or friend who had hip/knee surgery & $160(76.9)$ & $498(85.1)$ & 0.007 \\
\hline Good understanding of knee replacement & $106(51.0)$ & $365(64.9)$ & 0.001 \\
\hline \multicolumn{4}{|l|}{ Knowledge of TKR: risks and benefits } \\
\hline How often death from knee replacement, n (\%) & & & 0.257 \\
\hline Never & $29(14.7)$ & $75(13.4)$ & \\
\hline Extremely rare & $134(67.7)$ & $406(72.2)$ & \\
\hline Sometimes & $32(16.2)$ & $79(14.1)$ & \\
\hline Often & $3(1.5)$ & $2(0.4)$ & \\
\hline How long in hospital after knee replacement, n (\%) & & & 0.023 \\
\hline 1 to 3 days & $57(28.2)$ & $199(34.6)$ & \\
\hline 4 to 7 days & $79(39.1)$ & $250(43.5)$ & \\
\hline 1 to 2 weeks & $45(22.3)$ & $84(14.6)$ & \\
\hline$>2$ weeks & $21(10.4)$ & $42(7.3)$ & \\
\hline
\end{tabular}


Table 2 Characteristics of OA patients by willingness to undergo TKR (Continued)

\begin{tabular}{|c|c|c|c|}
\hline$<2$ weeks & $1(0.5)$ & $3(0.5)$ & \\
\hline 2 weeks to 1 month & $9(4.5)$ & $30(5.2)$ & \\
\hline 1 to 2 months & $44(22.1)$ & $140(24.3)$ & \\
\hline 2 to 6 months & $78(39.2)$ & $233(40.4)$ & \\
\hline 6 to 12 months & $50(25.1)$ & $146(25.3)$ & \\
\hline$>12$ months & $17(8.5)$ & $25(4.3)$ & \\
\hline How much pain after recovery, $\mathrm{n}(\%)$ & & & $<0.001$ \\
\hline None & $17(8.5)$ & $87(15.4)$ & \\
\hline A little & $74(37.0)$ & $267(47.2)$ & \\
\hline A moderate amount & $98(49.0)$ & $205(36.2)$ & \\
\hline An extreme amount & $11(5.5)$ & $7(1.2)$ & \\
\hline How much difficulty walking after recovery, n (\%) & & & $<0.001$ \\
\hline None & $14(6.9)$ & $120(21.0)$ & \\
\hline A little & $98(48.0)$ & $306(53.5)$ & \\
\hline A moderate amount & $84(41.2)$ & $134(23.4)$ & \\
\hline An extreme amount & $8(3.9)$ & $12(2.1)$ & \\
\hline Expectations of $T K R$, mean $\pm S D$ & $44.48 \pm 17.26$ & $53.40 \pm 13.90$ & $<0.001$ \\
\hline \multicolumn{4}{|l|}{ TKR utilization process, $n$ (\%) yes } \\
\hline Doctor ever discussed surgery & 65 (31.6) & $213(36.5)$ & 0.204 \\
\hline Referred to arthritis specialist & $67(33.0)$ & $172(29.9)$ & 0.404 \\
\hline Referred to surgeon & $101(49.3)$ & $268(47.0)$ & 0.580 \\
\hline Doctor recommended surgery & $47(22.8)$ & $130(22.4)$ & 0.906 \\
\hline Trust in physicians, mean \pm SD & $38.62 \pm 6.75$ & $39.77 \pm 6.65$ & 0.034 \\
\hline Trust in healthcare system, mean \pm SD & $26.11 \pm 6.17$ & $25.32 \pm 5.55$ & 0.090 \\
\hline
\end{tabular}

${ }^{\mathrm{a}} P$ value from Pearson chi square or $t$ test. ${ }^{\mathrm{b}}$ Individuals may be included in multiple categories. TKR total knee replacement, GED General Educational Development test

undergo TKR also had a higher score for expectations of HSS knee replacement $(p<0.001)$ and higher scores for trust in physicians $(p=0.034)$ compared to those who were unwilling to undergo TKR.

In stratified analyses, expectations of having 'none' or 'a little' difficulty walking after surgical recovery were related to willingness to undergo TKR among AA and WH participants (Additional files 1 and 2). Expectations of having 'none' or 'a little' pain after TKR was associated with willingness only among AAs (Additional file 1). Having a discussion about surgery with a doctor was associated with willingness only among WHs (Additional file 2). Higher scores for expectations of HSS knee replacement were associated with willingness to undergo TKR in both AA $(p<0.001)$ and WH participants $(p<0.001)$.

Willingness to undergo TKR was less often endorsed by AAs (62 \%) as compared with WHs (80\%), even after adjustment for recruitment site, sex, age, income, WOMAC total score, presence of private/group health insurance, and social support (adjusted odds ratio (OR) 0.43, $95 \% \mathrm{CI}$ $0.28,0.67)$. We also found a significant interaction between race and sex but the interaction was no longer significant in a fully adjusted model (Additional file 3).
Multivariate models: associations of potential mediators with willingness

After adjustment for recruitment site, sex, age, income and WOMAC total score, higher expectations of knee replacement was associated with willingness in the overall sample to undergo TKR and when stratified by race (Table 3). Among all participants, greater trust in physicians was also significantly associated with willingness even when adjusted for the same covariates $(p=0.047)$. Stepwise logistic regression in the full study sample showed that the following TKR-related knowledge items were associated with willingness to undergo TKR, after adjustment for the covariates: having family/ friend who had knee/hip surgery, having a good understanding of TKR, perceiving less pain after surgery, and perceiving less difficulty walking after surgery ( $p$ $<0.0001)$. These individual items and perceived decreased length of hospital stay were selected for inclusion in the mediation models (Additional file 4). Using the same process, the following TKR utilization process items were also selected for inclusion in the mediation models: having a discussion about surgery with a doctor, having been referred to an arthritis 
Table 3 Association by race between willingness to undergo TKR and religiosity, expectations of knee replacement, trust in physicians, and trust in healthcare

\begin{tabular}{|c|c|c|c|c|c|c|}
\hline & \multicolumn{2}{|l|}{ All } & \multicolumn{2}{|l|}{ White } & \multicolumn{2}{|l|}{ African-American } \\
\hline & $\mathrm{OR}(95 \% \mathrm{Cl})^{\mathrm{a}}$ & Wald Test ${ }^{b}$ & $\mathrm{OR}(95 \% \mathrm{Cl})^{\mathrm{a}}$ & Wald Test ${ }^{b}$ & $\overline{\mathrm{OR}}(95 \% \mathrm{Cl})^{\mathrm{a}}$ & Wald Test ${ }^{b}$ \\
\hline Religiosity $^{c}$ & $0.91(0.77,1.07)$ & 0.2441 & $1.09(0.89,1.35)$ & 0.404 & $0.79(0.60,1.06)$ & 0.114 \\
\hline Expectations regarding Total knee replacement ${ }^{c}$ & $1.54(1.31,1.82)$ & $<0.001$ & $1.63(1.28,2.07)$ & $<0.001$ & $1.48(1.16,1.90)$ & 0.002 \\
\hline Trust in physicians ${ }^{c}$ & $1.17(1.00,1.36)$ & 0.047 & $1.17(0.94,1.44)$ & 0.155 & $1.23(0.98,1.55)$ & 0.078 \\
\hline Trust in healthcare ${ }^{c}$ & $0.88(0.75,1.04)$ & 0.130 & $1.03(0.82,1.31)$ & 0.778 & $0.80(0.62,1.02)$ & 0.076 \\
\hline
\end{tabular}

${ }^{\mathrm{a}}$ Adjusted for recruitment site, sex, age, income and Western Ontario McMaster Index total score. ${ }^{\mathrm{b}} P$ values for Wald test were calculated using robust variance estimates. 'Modeled as linear categories (quartiles). OR odds ratio

specialist, and not having been referred to a surgeon (Additional file 4).

\section{Determinants of willingness to undergo TKR by race}

Table 4 shows the selected determinants of willingness to undergo TKR by patient race. Among WH participants, expectations of TKR $(p<0.001)$, TKR utilization process items $(p=0.039)$, and trust in healthcare $(p=0.068)$ were selected for model inclusion. Together, all were statistically significant determinants of willingness to undergo TKR $(p<0.001)$. For AA participants, TKR-related knowledge items $(p=0.031)$, expectations of TKR $(\mathrm{p}=0.084)$, religiosity $(p=0.045)$, and trust in physicians $(p=0.104)$ were selected for model inclusion. Together, all were

Table 4 Determinants of willingness to undergo total knee replacement (TKR) by race

\begin{tabular}{|c|c|c|}
\hline & White & African-American \\
\hline & OR $\left(95 \%()^{a}\right.$ & OR $(95 \% \mathrm{Cl})^{\mathrm{a}}$ \\
\hline \multicolumn{3}{|l|}{ Knowledge of TKR } \\
\hline Understands knee replacement & & $1.80(0.97,3.35)$ \\
\hline Length of hospital stay & & $0.81(0.58,1.13)$ \\
\hline Extent of pain after recovery & & $0.73(0.39,1.35)$ \\
\hline Extent of difficulty walking after recovery & & $0.66(0.37,1.16)$ \\
\hline \multicolumn{3}{|l|}{ Expectations of $T K R^{b}$} \\
\hline Second quartile & $1.70(0.86,3.33)$ & $1.85(0.76,4.51)$ \\
\hline Third quartile & $2.73(1.32,5.65)$ & $2.82(1.30,6.15)$ \\
\hline Highest quartile & $5.11(2.31,11.30)$ & $2.08(0.91,4.79)$ \\
\hline \multicolumn{3}{|l|}{ TKR process } \\
\hline Doctor ever discussed surgery & $1.96(1.05,3.68)$ & \\
\hline Referred to surgeon & $0.56(0.32,0.99)$ & \\
\hline \multicolumn{3}{|l|}{ Religiosity ${ }^{b}$} \\
\hline Second quartile & & $2.52(0.93,6.84)$ \\
\hline Third quartile & & $1.21(0.43,3.42)$ \\
\hline Highest quartile & & $0.85(0.32,2.26)$ \\
\hline \multicolumn{3}{|l|}{ Trust in physician ${ }^{b}$} \\
\hline Second quartile & & $2.14(0.89,5.15)$ \\
\hline Third quartile & & $1.01(0.46,2.25)$ \\
\hline Highest quartile & & $2.17(0.90,5.23)$ \\
\hline \multicolumn{3}{|l|}{ Trust in healthcare system ${ }^{b}$} \\
\hline Second quartile & $2.69(1.26,5.76)$ & \\
\hline Third quartile & $1.98(0.91,4.13)$ & \\
\hline Highest quartile & $1.58(0.75,3.31)$ & \\
\hline Likelihood ratio test, $p$ value & $<0.001$ & $<0.001$ \\
\hline
\end{tabular}

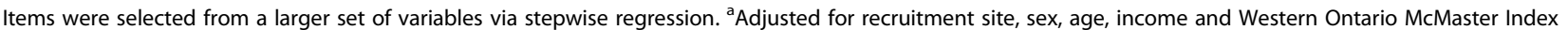

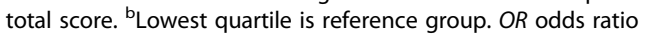


significant determinants of willingness to consider TKR $(p<0.001)$.

\section{Mediation of the association between race and willingness to undergo TKR}

Multivariable associations between race and willingness to undergo TKR are presented in Table 5. When adjusted for recruitment site, sex, age, income, WOMAC total score, health insurance, and social support, the odds of willingness to undergo TKR was $57 \%$ lower in AAs compared to WHs (OR 0.43, 95 \% CI 0.28, 0.67). Addition of the five selected TKR-related knowledge items attenuated this OR towards the null (OR 0.54, $95 \%$ CI 0.34, 0.87). Although the OR was attenuated towards the null for the unadjusted full model (OR 0.51, $95 \%$ CI 0.34, 0.78 vs. OR 0.41, $95 \%$ CI 0.30, 0.57), this was no longer true after adjustment for the covariates (OR 0.45, $95 \% \mathrm{CI} 0.27,0.76$ ).

\section{Discussion}

In this large sample of AA and WH patients with knee $\mathrm{OA}$, we found that determinants of patient preference for TKR differed between AAs and WHs. For AAs, better understanding of the procedure, a shorter hospital course, less post-surgical pain and walking difficulty, favorable expectations of surgery, less religiosity, and trust in physicians significantly influenced patient willingness to undergo TKR. On the other hand, favorable expectations of surgical outcomes, trust in healthcare, discussion with a physician, and not having received surgical referral were significant predictors of willingness among WHs. After controlling for socio-demographic and clinical factors, AAs were still much less willing to consider TKR surgery compared to WHs. Comprehending the process and outcomes of undergoing TKR attenuated this racial difference in patient preference.

Our study has various distinguishing characteristics from previous studies that examined racial differences in OA patients' treatment preferences. Early studies showed that AAs were less willing to consider joint replacement than WHs based on surveys of male veterans with knee OA [12, 13]. Subsequent studies had similar findings based on surveys of patients recruited from community-based clinics in Texas [20, 37] and North Carolina [21]. In contrast, our study surveyed patients regularly treated at academic facilities, the VA and community-based clinics. Hence, we were able to assemble a cohort of OA patients who differ in regards to gender, socioeconomic status and access to care. Several studies have also explored determinants of treatment preferences for joint replacement $[15,16,20,21]$. These studies focused on the roles of socio-demographic variables and patient knowledge of joint replacement, but minimally examined the roles of certain variables, including social support, religiosity and/or utilization process items. Finally, while previous studies merely controlled for patient race in their examinations of determinants of treatment preferences [12, 20, 21], our study is the first to identify specific determinants of the willingness of patients with knee OA to undergo TKR, by patient race.

Finding that good understanding of joint replacement and minimal perceptions of pain and difficulties after surgery were determinants of willingness to undergo TKR among AAs is consistent with previous OA studies $[12,16,20]$. Albeit, the North Carolina study [21] found that perceptions of joint replacement outcomes were not significantly associated with willingness to undergo knee

Table 5 Mediation of association between race and willingness to undergo total knee replacement (TKR)

\begin{tabular}{|c|c|c|c|}
\hline & Unadjusted & Adjusted $^{a}$ & Adjusted $^{b}$ \\
\hline & OR $(95 \% \mathrm{Cl})$ & OR $(95 \% \mathrm{Cl})$ & OR $(95 \% \mathrm{Cl})$ \\
\hline Primary predictor, race & $0.41(0.30,0.57)$ & $0.45(0.29,0.70)$ & $0.43(0.28,0.67)$ \\
\hline \multicolumn{4}{|l|}{ Potential mediators } \\
\hline Knowledge of TKR ${ }^{c}$ & $0.57(0.39,0.82)$ & $0.55(0.35,0.88)$ & $0.54(0.34,0.87)$ \\
\hline Expectations regarding TKR & $0.44(0.32,0.62)$ & $0.47(0.30,0.72)$ & $0.44(0.28,0.70)$ \\
\hline TKR process ${ }^{\mathrm{d}}$ & $0.41(0.29,0.57)$ & $0.42(0.26,0.66)$ & $0.39(0.26,0.62)$ \\
\hline Religiosity & $0.41(0.29,0.57)$ & $0.43(0.27,0.67)$ & $0.42(0.26,0.66)$ \\
\hline Trust in physician & $0.41(0.30,0.57)$ & $0.44(0.28,0.67)$ & $0.43(0.27,0.66)$ \\
\hline Trust in healthcare system & $0.42(0.30,0.58)$ & $0.45(0.29,0.69)$ & $0.43(0.27,0.67)$ \\
\hline Full modele & $0.51(0.34,0.78)$ & $0.45(0.27,0.74)$ & $0.45(0.27,0.76)$ \\
\hline
\end{tabular}

${ }^{a}$ Adjusted for recruitment site, sex, age, income and Western Ontario McMaster Index totalscore. ${ }^{b}$ Additionally adjusted for private/group insurance and social support. 'Knowledge items selected for model inclusion: family/friend had hip or knee surgery, understands knee replacement, length of hospital stay, extent of pain after recovery, extent of difficulty walking after recovery. ${ }^{\mathrm{d}}$ TKR process items selected for model inclusion: doctor ever discussed surgery, referred to arthritis

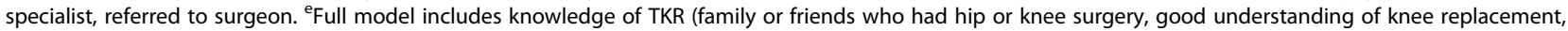
hospital length of stay after TKR, residual pain after recovery, residual difficulty walking after recovery), expectations of TKR (quartiles), TKR process items (ever discussed TKR with a physician, referred to arthritis specialist, referred to surgeon), religiosity (quartiles), trust in physician (quartiles), trust in healthcare system (quartiles). $O R$ odds ratio 
or hip replacement surgery. Regardless, better knowledge of the process and outcomes of joint replacement seems to also minimize the racial difference in patient preference for the procedure.

In similar fashion, the knee OA VA study suggested that differences in expectations of hospital course, pain and function after joint replacement fully mediated racial differences in willingness to consider joint replacement [12]. Our study did not support this specific finding of the VA study. Our study did link greater expectations with increased willingness to consider TKR in AAs and WHs with OA separately, however.

We also found that minimal levels of religiosity determined willingness among AAs to undergo TKR. Indeed, many studies have shown that prayer is a common selfcare treatment used by AAs [13, 38, 39]. Perceiving prayer as helpful also accounted for differences between AA and WH veterans in their attitudes toward TKR [13]. In contrast, in the Texas study strength in religious belief was unrelated to patient preference for TKR [20]. However, this latter study used a single-item rather than a four-item, ordinal scale to measure the level of religiosity, and multi-item scales tend to outperform single items in terms of predictive validity [40].

Trust in physicians was relevant in AA OA patients' treatment preferences for TKR. In parallel, trust in healthcare was important in WH OA patients' preferences. The role of patient trust in providers and the healthcare system in determining preferences has been observed in studies of patients with OA and other diseases [20,41]. Moreover, mistrust of healthcare organizations and health professionals had been associated with less utilization of health services in other patient populations [42, 43].

The implications of our findings are highly relevant. Decision aids and other educational tools may be designed to educate patients about the benefits and risks of the procedure, and expectations for during and after the procedure. Albeit limited, a few patient-centered educational programs to address such matters have already been developed [44]. Educational strategies and training targeted towards healthcare professionals may also be developed to improve patient trust in physicians and the healthcare system. As a consequence, we may improve OA patients' preference towards more effective and evidence-based treatments, including TKR. Eventually, we may be able to personalize intervention programs and reduce racial disparities in the utilization of TKR among OA patients.

There are limitations to consider in interpreting the study results. First, the cross-sectional design of this study limits our ability to infer a causal relationship. For instance, we cannot determine whether unwillingness to undergo TKR among WHs was due to prior surgical referral or whether not receiving a surgical referral for TKR was due to unwillingness to have the procedure done. The latter is more likely than the former, as patient preferences for treatments for OA were likely to have been established during the early stages of the disease. Second, we did not determine whether patients were anticipating TKR in the near future. Participants who were in this situation might have been more willing to undergo surgery than patients for whom TKR was a mere hypothetical option. This question was excluded from the survey to minimize patient burden. Third, we included only AAs and WHs, and our findings may not be generalizable to patients from other racial groups. Evaluation of the treatment preferences among other racial and ethnic minorities should be conducted in the future.

\section{Conclusions}

We have identified relatively modifiable factors that determine patient willingness to consider joint replacement, by patient race. Expectations of joint replacement surgical outcomes were associated with preferences for TKR in both races. Adequate understanding of the procedure, minimal perceptions of pain and difficulties after surgery, and higher trust in physicians determined willingness to undergo joint replacement among AAs. Among WHs, trust in the healthcare system and having a surgical discussion with a physician also determined willingness. The findings of this study may lead to the development of highly specific programs that could reduce or possibly eliminate racial and ethnic disparities in the utilization of joint replacement surgery and other clinical outcomes of patients with OA. Hence, we may be able to enhance the quality of care of all patients with this debilitating disease.

\section{Additional files}

Additional file 1: Knowledge, attitudes and beliefs of African-American OA patients by willingness to undergo TKR Surgery. (DOCX 25 kb)

Additional file 2: Knowledge, attitudes and beliefs of White OA patients by willingness to undergo TKR Surgery. (DOCX 25 kb) Additional file 3: Logistic regression analyses of willingness and race, stratified by sex. (DOCX $25 \mathrm{~kb}$ )

Additional file 4: Significant associations $(p<0.20)$ of willingness to undergo TKR surgery with TKR knowledge and utilization process items. (DOCX $15 \mathrm{~kb})$

\section{Abbreviations}

AA: African-American; Cl: confidence interval; HSS: Hospital for Special Surgery; MOS-SSS: Medical Outcomes Study-social support scale;

OA: osteoarthritis; OR: odds ratio; PHQ-9: Patient Health Questionnaire-9; SF12: Short Form Health Survey; TKR: total knee replacement; VA: Veterans Affairs; WH: white; WOMAC: Western Ontario McMaster Index.

\section{Competing interests}

The authors declare that they have no competing interests. 


\section{Authors' contributions}

CK and SI were responsible for the study concept and design. All authors acquired, analyzed, and interpreted the data. EV was responsible for creating the first draft of the manuscript. All authors critically revised the manuscript for important intellectual content. YC and $\mathrm{MH}$ were responsible for the statistical analysis. CK and SI were responsible for study supervision. All authors read and approved the final version of the manuscript.

\section{Acknowledgements}

This study was supported by the $\mathrm{NIH} /$ National Institute of Arthritis and Musculoskeletal Skin Diseases (Grant P60-AR-054731). Dr. Ibrahim is supported in part by a K24 Mid-Career Development Award from the National Institute of Arthritis and Musculoskeletal and Skin Disorders (K24AR055259).

\section{Author details}

${ }^{1}$ University of Arizona School of Medicine and University of Arizona Arthritis Center, 1501 N. Campbell Ave., PO Box 245093, Tucson, Arizona 85724, USA. ${ }^{2}$ University of Pittsburgh School of Public Health, 130 De Soto St., 127 Parran Hall, Pittsburgh, Pennsylvania 15261, USA. ${ }^{3}$ University of Pittsburgh School of Medicine, 130 North Bellefield Ave., 4th Floor, Pittsburgh, Pennsylvania 15213, USA. ${ }^{4}$ University of Pennsylvania Perelman School of Medicine and Philadelphia VA Medical Center, 3900 Woodland Ave., Philadelphia, Pennsylvania 19104, USA.

Received: 27 May 2015 Accepted: 17 November 2015

\section{Published online: 03 December 2015}

\section{References}

1. Murphy L, Schwartz TA, Helmick CG, Renner JB, Tudor G, Koch G, et al. Lifetime risk of symptomatic knee osteoarthritis. Arthritis Rheum. 2008;59: 1207-13.

2. Lawrence RC, Felson DT, Helmick CG, Arnold LM, Choi H, Deyo RA, et al. Estimates of the prevalence of arthritis and other rheumatic conditions in the United States. Part II. Arthritis Rheum. 2008:58:26-35.

3. Michaud CM, McKenna MT, Begg S, Tomijima N, Majmudar M, Bulzacchelli MT, et al. The burden of disease and injury in the United States 1996. Popul Health Metr. 2006;4:11

4. Zhang W, Nuki G, Moskowitz RW, Abramson S, Altman RD, Arden NK, et al. OARSI recommendations for the management of hip and knee osteoarthritis: part III: Changes in evidence following systematic cumulative update of research published through January 2009. Osteoarthritis Cartilage. 2010;18:476-99.

5. Skinner J, Weinstein JN, Sporer SM, Wennberg JE. Racial, ethnic, and geographic disparities in rates of knee arthroplasty among Medicare patients. N Engl J Med. 2003:349:1350-9.

6. Escarce JJ, Epstein KR, Colby DC, Schwartz JS. Racial differences in the elderly's use of medical procedures and diagnostic tests. Am J Public Health. 1993:83:948-54

7. Ibrahim SA. Racial variations in the utilization of knee and hip joint replacement: an introduction and review of the most recent literature. Cur Orthop Pract. 2010;21:126-31.

8. Dunlop DD, Manheim LM, Song J, Sohn MW, Feinglass JM, Chang HJ, et al. Age and racial/ethnic disparities in arthritis-related hip and knee surgeries. Med Care. 2008:46:200-8.

9. Hawker GA, Guan J, Croxford R, Coyte PC, Glazier RH, Harvey BJ, et al. A prospective population-based study of the predictors of undergoing total joint arthroplasty. Arthritis Rheum. 2006;54:3212-20.

10. Ibrahim SA, Siminoff LA, Burant CJ, Kwoh CK. Variation in perceptions of treatment and self-care practices in elderly with osteoarthritis: a comparison between African American and white patients. Arthritis Rheum. 2001;45: 340-5.

11. Ibrahim SA, Siminoff LA, Burant CJ, Kwoh CK. Understanding ethnic differences in the utilization of joint replacement for osteoarthritis: the role of patient-level factors. Med Care. 2002;40:144-51.

12. Ibrahim SA, Simin off LA, Burant CJ, Kwoh CK. Differences in expectations of outcome mediate African American/white patient differences in "willingness" to consider joint replacement. Arthritis Rheum. 2002:46:2429-35.

13. Ang DC, Ibrahim SA, Burant CJ, Siminoff LA, Kwoh CK. Ethnic differences in the perception of prayer and consideration of joint arthroplasty. Med Care. 2002:40:471-6.
14. Karlson EW, Daltroy LH, Liang MH, Eaton HE, Katz JN. Gender differences in patient preferences may underlie differential utilization of elective surgery. Am J Med. 1997;102:524-30.

15. Hawker GA, Wright JG, Coyte PC, Williams JI, Harvey B, Glazier R, et al. Determining the need for hip and knee arthroplasty: the role of clinical severity and patients' preferences. Med Care. 2001;39:206-16.

16. Hawker GA, Wright JG, Badley EM, Coyte PC. Perceptions of, and willingness to consider, total joint arthroplasty in a population-based cohort of individuals with disabling hip and knee arthritis. Arthritis Rheum. 2004;51:635-41.

17. Figaro MK, Russo PW, Allegrante JP. Preferences for arthritis care among urban African Americans: "I don't want to be cut". Health Psychol. 2004;23: 324-9.

18. Ajzen I, Fishbein M. Attitudes and the attitude-behavior relation: reasoned and automatic processes. In: Stroebe W, Hewstone M, editors. European review of social psychology. Chichester, England: Wiley; 2000.

19. Groeneveld PW, Kwoh CK, Mor MK, Appelt CJ, Geng M, Gutierrez JC, et al. Racial differences in expectations of joint replacement surgery outcomes. Arthritis Rheum. 2008:59:730-7.

20. Suarez-Almazor ME, Souchek J, Kelly PA, O'Malley K, Byrne M, Richardson M, et al. Ethnic variation in knee replacement: patient preferences or uninformed disparity? Arch Intern Med. 2005;165:1117-24.

21. Allen KD, Golightly YM, Callahan LF, Helmick CG, Ibrahim SA, Kwoh CK, et al. Race and sex differences in willingness to undergo total joint replacement: the Johnston County Osteoarthritis Project. Arthritis Care Res (Hoboken). 2014;66:1193-202

22. Levinson W, Hudak PL, Feldman JJ, Frankel RM, Kuby A, Bereknyei S, et al. "It's not what you say ...": racial disparities in communication between orthopedic surgeons and patients. Med Care. 2008:46:410-6.

23. Vina ER, Cloonan YK, Ibrahim SA, Hannon MJ, Boudreau RM, Kwoh CK. Race, sex, and total knee replacement consideration: role of social support. Arthritis Care Res (Hoboken). 2013;65:1103-11.

24. Davis MA, Ettinger WH, Neuhaus JM. Obesity and osteoarthritis of the knee: evidence from the National Health and Nutrition Examination Survey (NHANES I). Semin Arthritis Rheum. 1990;20:34-41.

25. Bellamy N, Buchanan WW, Goldsmith CH, Campbell J, Stitt LW. Validation study of WOMAC: a health status instrument for measuring clinically important patient relevant outcomes to antirheumatic drug therapy in patients with osteoarthritis of the hip or knee. J Rheumatol. 1988;15:1833-40.

26. Davis MA, Ettinger WH, Neuhaus JM, Barclay JD, Segal MR. Correlates of knee pain among US adults with and without radiographic knee osteoarthritis. J Rheumatol. 1992;19:1943-9.

27. Altman R, Asch E, Bloch D, Bole G, Borenstein D, Brandt K, et al. Development of criteria for the classification and reporting of osteoarthritis. Classification of osteoarthritis of the knee. Diagnostic and therapeutic criteria committee of the american rheumatism association. Arthritis Rheum. 1986;29:1039-49.

28. Hawker GA, Wright JG, Coyte PC, Williams JI, Harvey B, Glazier R, et al. Differences between men and women in the rate of use of hip and knee arthroplasty. N Engl J Med. 2000;342:1016-22.

29. Sherbourne CD, Stewart AL. The MOS social support survey, Soc Sci Med. 1991;32:705-14.

30. Chaudhry S, Jin L, Meltzer D. Use of a self-report-generated charlson comorbidity index for predicting mortality. Med Care. 2005;43:607-15.

31. Ware Jr JE, Kosinski M, Bjorner JB, Turner-Bowker DM, Gandek B, Maruish ME. User's Manual for the SF-36v2TM Health Survey. 2nd ed. Lincoln, RI: Quality Metric Incorporated; 2007.

32. Kroenke K, Spitzer RL, Williams JB. The PHQ-9: validity of a brief depression severity measure. J Gen Intern Med. 2001;16:606-13.

33. Sullivan KT. Understanding the relationship between religiosity and marriage: an investigation of the immediate and longitudinal effects of religiosity on newlywed couples. J Fam Psychol. 2001;15:610-26.

34. Mancuso CA, Sculco TP, Wickiewicz TL, Jones EC, Robbins L, Warren RF, et al. Patients' expectations of knee surgery. J Bone Joint Surg Am. 2001:83-A:1005-12.

35. Kao AC, Green DC, Zaslavsky AM, Koplan JP, Cleary PD. The relationship between method of physician payment and patient trust. JAMA. 1998;280: $1708-14$.

36. Huang B, Sivaganesan S, Succop P, Goodman E. Statistical assessment of mediational effects for logistic mediational models. Stat Med. 2004:23:2713-28.

37. Byrne MM, Souchek J, Richardson M, Suarez-Almazor M. Racial/ethnic differences in preferences for total knee replacement surgery. J Clin Epidemiol. 2006;59:1078-86. 
38. Bill-Harvey D, Rippey RM, Abeles M, Pfeiffer CA. Methods used by urban, low-income minorities to care for their arthritis. Arthritis Care Res. 1989;2: 60-4.

39. Ibrahim SA, Zhang A, Mercer MB, Baughman M, Kwoh CK. Inner city African-American elderly patients' perceptions and preferences for the care of chronic knee and hip pain: findings from focus groups. J Gerontol A Bio Sci Med Sci. 2004;59:1318-22.

40. Diamantopoulos A, Sarstedt M, Fuchs C, Wilczynski P, Kaiser S. Guidelines for choosing between multi-item and single-item scales for construct measurement: a predictive validity perspective. J Acad Mark Sci. 2012;40: 434-49.

41. Vina ER, Utset TO, Hannon MJ, Masi CM, Roberts N, Kwoh CK. Racial differences in treatment preferences among lupus patients: a two-site study. Clin Exp Rheumatol. 2014;32:680-8.

42. LaVeist TA, Nickerson KJ, Bowie JV. Attitudes about racism, medical mistrust, and satisfaction with care among African American and white cardiac patients. Med Care Res Rev. 2000:57 Suppl 1:146-61.

43. LaVeist TA, Isaac LA, Williams KP. Mistrust of health care organizations is associated with underutilization of health services. Health Serv Res. 2009:44: 2093-105

44. Ibrahim SA, Hanusa BH, Hannon MJ, Kresevic D, Long J, Kwoh CK. Willingness and access to joint replacement among African American patients with knee osteoarthritis: a randomized, controlled intervention. Arthritis Rheum. 2013;65:1253-61.

\section{Submit your next manuscript to BioMed Central} and we will help you at every step:

- We accept pre-submission inquiries

- Our selector tool helps you to find the most relevant journal

- We provide round the clock customer support

- Convenient online submission

- Thorough peer review

- Inclusion in PubMed and all major indexing services

- Maximum visibility for your research 